\title{
A Comparative Analysis of Cytochrome P450 Activities in Paired Liver and Small Intestinal Samples from Patients with Obesity ${ }^{\mathbb{}}$
}

\author{
Veronica Krogstad, (D) Alexandra Peric, Ida Robertsen, Marianne K. Kringen, Christine Wegler, \\ Philip Carlo Angeles, Jøran Hjelmesæth, Cecilia Karlsson, Shalini Andersson, (DPer Artursson, \\ Anders Åsberg, Tommy B. Andersson, and Hege Christensen
}

Section for Pharmacology and Pharmaceutical Biosciences, Department of Pharmacy, University of Oslo, Oslo, Norway (V.K., I.R., A.Å., H.C.); Department of Transplantation Medicine, Oslo University Hospital, Rikshospitalet, Oslo, Norway (V.K., A.Å.); Research and Early Development, Cardiovascular, Renal and Metabolism, BioPharmaceuticals R\&D, AstraZeneca Gothenburg, Gothenburg, Sweden (A.P., C.W., S.A., T.B.A.); Center for Psychopharmacology, Diakonhjemmet Hospital, Oslo, Norway (M.K.K.); Department of Health Sciences, OsloMet-Oslo Metropolitan University, Oslo, Norway (M.K.K.); Department of Pharmacy, Uppsala University, Uppsala, Sweden (C.W., P.A.); The Morbid Obesity Centre, Vestfold Hospital Trust, Tønsberg, Norway (P.C.A., J.H.); Department of Surgery, Vestfold Hospital Trust, Tønsberg, Norway (P.C.A.); Department of Endocrinology, Morbid Obesity and Preventive Medicine, Institute of Clinical Medicine, University of Oslo, Oslo, Norway (J.H.); Late-Stage Development, Cardiovascular, Renal and Metabolism, BioPharmaceuticals R\&D, AstraZeneca Gothenburg, Gothenburg, Sweden (C.K.); Department of Molecular and Clinical Medicine, Institute of Medicine, Sahlgrenska Academy, University of Gothenburg, Gothenburg, Sweden (C.K.); and Department of Physiology and Pharmacology, Section of Pharmacogenetics, Karolinska Institutet, Stockholm, Sweden (T.B.A.)

Received May 11, 2019; accepted October 28, 2019

\section{ABSTRACT}

The liver and small intestine restrict oral bioavailability of drugs and constitute the main sites of pharmacokinetic drug-drug interactions. Hence, detailed data on hepatic and intestinal activities of drug metabolizing enzymes is important for modeling drug disposition and optimizing pharmacotherapy in different patient populations. The aim of this study was to determine the activities of seven cytochrome P450 (P450) enzymes in paired liver and small intestinal samples from patients with obesity. Biopsies were obtained from 20 patients who underwent Roux-en-Y gastric bypass surgery following a 3-week low-energy diet. Individual hepatic and intestinal microsomes were prepared and specific probe substrates in combined incubations were used for determination of CYP1A2, CYP2B6, CYP2C8, CYP2C9, CYP2C19, CYP2D6, and CYP3A activities. The activities of CYP2C8, CYP2C9, CYP2D6, and CYP3A were quantified in both human liver microsomes (HLM) and human intestinal microsomes (HIM), while the activities of CYP1A2, CYP2B6, and CYP2C19 were only quantifiable in HLM. Considerable interindividual variability was present in both HLM (9- to 23-fold) and HIM (5- to 55-fold). The median metabolic HLM/HIM ratios varied from 1.5 for CYP3A to 252 for CYP2C8. The activities of CYP2C9 in paired HLM and HIM were positively correlated $(r=0.74, P<0.001)$, while no interorgan correlations were found for activities of CYP2C8, CYP2D6, and CYP3A $(P>0.05)$. Small intestinal CYP3A activities were higher in females compared with males $(P<0.05)$. Hepatic CYP2B6 activity correlated negatively with body mass index $(r=-0.72, P<0.001)$. These data may be useful for further in vitro-in vivo predictions of drug disposition in patients with obesity.

\section{SIGNIFICANCE STATEMENT}

Hepatic and intestinal drug metabolism is the key determinant of oral drug bioavailability. In this study, paired liver and jejunum samples were obtained from 20 patients with obesity undergoing gastric bypass surgery following a 3-week low-energy diet. We determined the hepatic and small intestinal activities of clinically important P450 enzymes and provide detailed enzyme kinetic data relevant for predicting in vivo disposition of P450 substrates in this patient population.

\section{Introduction}

The liver and small intestine are the primary sites of drug metabolism, influencing both oral bioavailability and clearance and thereby the systemic exposure of drugs. The main group of drug metabolizing enzymes is the cytochrome P450 (P450) group, in which the CYP1-3 families are estimated to be responsible for $70 \%-80 \%$ of all phase I drug metabolism (Ingelman-Sundberg, 2005). The CYP3A subfamily, comprising the isoforms CYP3A4 and CYP3A5 in adults, is considered

https://doi.org/10.1124/dmd.119.087940.

S This article has supplemental material available at dmd.aspetjournals.org. clinically to be the most important due to its broad substrate specificity. A wide range of drug metabolizing $\mathrm{P} 450$ enzymes is expressed in the liver, including CYP1A2, CYP2A6, CYP2B6, CYP2C8, CYP2C9, CYP2C19, CYP2D6, CYP2E1, and CYP3A4/5 (Shimada et al., 1994; Achour et al., 2014). In the small intestine, a more limited number of P450s is expressed at relevant levels and the CYP3A subfamily is estimated to represent about $80 \%$ of the total intestinal P450 content, followed by CYP2C9, which accounts for about 15\% (Paine et al., 2006). Additionally, the hepatic levels of P450 enzymes are considerably higher than in the intestine, and the total small intestinal CYP3A amount has been estimated to equal approximately $1 \%$ of that in the liver (Paine et al., 1997). However, there is large interindividual variability in

ABBREVIATIONS: ACN, acetonitrile; BMI, body mass index; $\mathrm{CL}_{\text {int,u }}$, unbound intrinsic clearance; HIM, human intestinal microsomes; $\mathrm{HLM}$, human liver microsomes; $K_{\mathrm{m}}$, Michaelis constant; $K_{\mathrm{m}, \mathrm{u}}$, unbound Michaelis constant; P450, cytochrome P450. 
the expression and activity of the various P450 isoforms (Obach et al., 2001; Paine et al., 2006; Yang et al., 2012; Achour et al., 2014). This may be partly due to genetic polymorphisms, but other factors such as disease state, dietary constituents, and concomitant use of drugs can also affect P450 activity and hence the pharmacokinetics of P450 substrates (Morgan et al., 2008; Zanger and Schwab, 2013; Shah and Smith, 2015).

Obesity, defined by a body mass index (BMI) of $30 \mathrm{~kg} / \mathrm{m}^{2}$ or above, has been associated with altered pharmacokinetics of $\mathrm{P} 450$ substrates, but the underlying mechanisms have not been clarified (Brill et al., 2012). Since polypharmacy is common due to comorbidities, it is important to gain a more in-depth understanding of interindividual variability in drug metabolizing capacity in this patient group. Physiologically based pharmacokinetic models are important tools in predicting drug disposition, and in order to perform high-quality modeling of oral bioavailability it is important to have detailed data on $\mathrm{P} 450$ activities at the major sites of drug metabolism, i.e., the liver and small intestine. Data on P450 expression and activity in paired human tissue samples are limited (Paine et al., 1997; Lin et al., 2002; Läpple et al., 2003; von Richter et al., 2004; Ulvestad et al., 2013; Drozdzik et al., 2018; Lloret-Linares et al., 2019), and to the authors' knowledge no studies have compared hepatic and intestinal activities in patients with obesity. Hence, the aim of this study was to determine the interindividual variability and covariation of microsomal CYP1A2, CYP2B6, CYP2C8, CYP2C9, CYP2C19, CYP2D6, and CYP3A activities in paired liver and small intestinal biopsies from 20 patients with severe obesity.

\section{Materials and Methods}

Chemicals. Tris base, protease inhibitor cocktail tablets (Complete, Mini), HEPES buffer, and reduced $\beta$-NADPH were purchased from Sigma-Aldrich (St. Louis, MO). Sucrose and methanol were obtained from Merck (Kenilworth, $\mathrm{NJ}$ ), acetonitrile (ACN) was obtained from Fisher Scientific (Waltham, MA), and EDTA was purchased from Ferak (Berlin, Germany). Phosphate buffer, prepared from dipotassium hydrogen phosphate and potassium dihydrogen phosphate, was obtained from Sigma-Aldrich. P450 probe substrates, metabolites, and internal standard (5,5-diethyl-1,3-diphenyl-2-iminobarbituric acid) were prepared in-house or obtained from Sigma-Aldrich. High-purity water was prepared with a Milli-Q Water Purification System (Merck).

Patients. Twenty patients (six males and 14 females) with severe obesity (BMI $\geq 40$ or $35-40 \mathrm{~kg} / \mathrm{m}^{2}$; combined with at least one obesity-related comorbidity) underwent Roux-en-Y gastric bypass surgery in the COCKTAIL study (trial registration number NCT02386917) (Hjelmesæth et al., 2018). Anthropometric measurements and blood samples for clinical chemistry analyses were collected the day before surgery. Total body weight was determined using the Inbody 720, Body Composition Analyzer (Biospace, Korea). Height was measured to the nearest $1 \mathrm{~cm}$ and BMI was calculated as the weight (in kilograms) divided by the square of the height (in meters). Measurements of waist and hip circumference were standardized and performed by dedicated study personnel. Clinical chemistry analyses were performed at the Department of Laboratory Medicine at Vestfold Hospital Trust. High-sensitivity C-reactive protein was analyzed at Fürst Medical Laboratory (Oslo, Norway). The patients were subjected to a 3-week low-energy diet $(<1200 \mathrm{kcal} / \mathrm{day})$ before surgery. None of the patients received drugs before or during surgery that were known to alter the activities of the P450 enzymes investigated in the current study. This study complied with the Declaration of Helsinki. The study protocol was approved by the Regional Committee for Medical and Health Research Ethics (2013/2379/ REK sørøst A), and all patients signed a written informed consent. Since this was an exploratory study, an a priori power calculation was not performed.

Small Intestinal and Hepatic Biopsies. Paired jejunal and liver biopsies were obtained from each patient during surgery. The distal end of the biliopancreatic limb (proximal jejunum) was resected and removed to allow for biopsy harvesting. Liver tissue was obtained from parenchyma, by cutting a sample close to the edge of the right liver lobe with cold scissors. The tissue samples were transferred into individual cryotubes, snap frozen in liquid nitrogen immediately after sampling, and stored at $-80^{\circ} \mathrm{C}$ until analysis.

Preparation of Microsomal Fractions. The liver $(100 \pm 81 \mathrm{mg})$ and jejunal $(687 \pm 277 \mathrm{mg})$ biopsies were thawed on ice and homogenates were prepared with a Potter-Elvehjem homogenizer $(5 \mathrm{ml})$ in buffer containing $0.32 \mathrm{~mol} / \mathrm{l}$ sucrose, $10 \mathrm{mmol} / \mathrm{l}$ Tris base, and protease inhibitor cocktail (Complete, Mini, one tablet per $10 \mathrm{ml}$ buffer). The homogenization was performed at $2000 \mathrm{rpm}$ in two rounds of 10 strokes for the jejunum samples and two rounds of eight strokes for the liver samples. The samples were placed on ice between rounds. The homogenate was centrifuged at $7400 \mathrm{~g}$ for 10 minutes $\left(4^{\circ} \mathrm{C}\right)$ and the pellet was discarded. The supernatant was centrifuged at $104,000 \mathrm{~g}$ for 60 minutes $\left(4^{\circ} \mathrm{C}\right)$, and the microsomal pellet was resuspended in buffer containing $0.25 \mathrm{~mol} / \mathrm{l}$ sucrose, $10 \mathrm{mmol} / 1$ HEPES buffer, and $2 \mathrm{mmol} / \mathrm{l} \mathrm{EDTA}$. The microsomes were stored at $-80^{\circ} \mathrm{C}$ until $\mathrm{P} 450$ activity analysis. A small volume $(10 \mu \mathrm{l})$ was stored separately for determination of microsomal protein concentration (BioRad protein assay, based on the Bradford dye-binding method) (Bradford, 1976).

Probe Substrates. Specific probe substrates in combined incubations were used to study the activities of the seven P450 enzymes: bupropion (CYP2B6), amodiaquine (CYP2C8), diclofenac (CYP2C9), bufuralol (CYP2D6), midazolam (CYP3A), phenacetin (CYP1A2), and $S$-mephenytoin (CYP2C19) (Table 1) (Spaggiari et al., 2014). The probe substrates were divided into two cocktails to minimize interactions (unpublished data) (Table 1).

Microsomal Incubation. Preliminary assessments of microsomal protein concentration and incubation time to ensure linear metabolite formation over time were performed in pooled human liver microsomes (HLM) (obtained commercially) for all probe substrates. Pooled HLM were also used in the initial experiments to evaluate repeatability in the determination of the $V_{\max }$ and Michaelis constant $\left(K_{\mathrm{m}}\right)$ values (coefficient of variation $<15 \%$ ). Activity incubations were carried out in 96 -well plates at $37^{\circ} \mathrm{C}$ and $300 \mathrm{rpm}$ with hepatic and intestinal microsomal protein concentrations of $0.1-1 \mathrm{mg} / \mathrm{ml}$ (depending on available tissue amount) in $1 \mathrm{mmol} / \mathrm{l}$ phosphate buffer $(\mathrm{pH} 7.4)$ with $1 \mathrm{mmol} / 1 \mathrm{NADPH}$. The microsome mixtures were preheated at $37^{\circ} \mathrm{C}$ for 15 minutes and reactions were initiated by adding probe substrate cocktail 1 or 2 at eight different concentrations (Table 1). Blank samples containing buffer, $\mathrm{NADPH}$, and substrates were also included. Methanol, in concentrations $\leq 1 \%$, was used in the incubations to keep the substrates in solution. At 20 minutes, the incubation was stopped by transferring $20 \mu \mathrm{l}$ of the incubation mixture to $60 \mu \mathrm{l}$ of ice-cold ACN containing internal standard. The samples were centrifuged at $3220 \mathrm{~g}$ for 20 minutes $\left(4^{\circ} \mathrm{C}\right)$, and the supernatant was transferred to a new plate and mixed with an equal volume of Milli-Q water. For samples with high analyte concentration, the 1:1 dilution was further diluted 1:20 with $30 \% \mathrm{ACN}$.

TABLE 1

Substrates, substrate concentrations, and metabolites used as probe reactions for the respective P450 enzyme activities

\begin{tabular}{lllcl}
\hline & Enzyme & Substrate & Substrate Concentration Range & Metabolite \\
\hline \multirow{4}{*}{ Cocktail 1 } & & & $\mu M$ & OH-bupropion \\
& CYP2B6 & Bupropion & $1.6-200$ & $N$-Desethylamodiaquine \\
& CYP2C8 & Amodiaquine & $0.4-50$ & 4-OH-diclofenac \\
& CYP2C9 & Diclofenac & $0.8-100$ & 1-OH-bufuralol \\
& CYP2D6 & Bufuralol & $0.8-100$ & $1-O H-$-midazolam \\
Cocktail 2 & CYP3A & Midazolam & $0.8-100$ & Paracetamol \\
& CYP1A2 & Phenacetin & $1.6-200$ & 4-OH-mephenytoin \\
& CYP2C19 & $S$-Mephenytoin & $0.8-100$ & \\
\hline
\end{tabular}


Liquid Chromatography-Tandem Mass Spectrometry. Quantification of probe metabolites was performed using a triple quadrupole mass spectrometer coupled to an ACQUITY UPLC I-class system (Waters XevoTM TQ-S; Waters Corporation, Milford, MA) equipped with an electrospray ionization source. The mass spectrometer was operated in multiple reactions monitoring mode. Samples were ionized in positive mode and the ion source was set to a temperature of $150^{\circ} \mathrm{C}$. The ionization source parameters were as follows: capillary voltage, $0.60 \mathrm{kV}$; cone voltage, $60 \mathrm{~V}$; and source offset voltage, $60 \mathrm{~V}$. The gas settings were as follows: cone gas, $150 \mathrm{l} / \mathrm{h}$; desolvation gas, $1200 \mathrm{l} / \mathrm{h}$; and nebulizer gas flow, 7 bar. Dwell time per transition was set to 0.010 seconds and mass transitions were determined by QuanOptimize (Waters Corporation) (Supplemental Table 1).

Chromatography was performed on an ACQUITY UPLC HSS T3 column $(2.1 \times 50 \mathrm{~mm}, 1.8 \mu \mathrm{m}$ particle size $)$ at $40^{\circ} \mathrm{C}$. The flow rate was $0.8 \mathrm{ml} / \mathrm{min}$ and the injection volume was $5 \mu$ l. The mobile phases consisted of A: water, $0.2 \%(\mathrm{v} / \mathrm{v})$ formic acid, and $2 \%(\mathrm{v} / \mathrm{v}) \mathrm{ACN}$; and $\mathrm{B}: \mathrm{ACN}$ and $0.2 \%(\mathrm{v} / \mathrm{v})$ formic acid. The linear gradient was as follows: $0.2 \% \mathrm{~B}$ from 0.00 to 0.30 minutes, $0.2 \%-95 \%$ B from 0.30 to 1.60 minutes, $95 \%$ B from 1.60 to 2.10 minutes, 95\%-0.2\% B from 2.10 to 2.11 minutes, and $0.2 \%$ B from 2.11 to 2.50 minutes. The run time was 2.50 minutes and the equilibration time between injections was 0.39 minutes.

Data were processed using TargetLynx software (Waters Corporation). Concentrations were determined against matrix-spiked calibration standards over a range of $0.005-20 \mu \mathrm{mol} / 1$. The calibration samples contained all seven metabolites (Table 1) and were analyzed in triplicate. The calibration curves were fitted by weighted $\left(1 / x^{2}\right)$ linear least-square regression. Backcalculated values of calibrators within $80 \%-120 \%$ of nominal values (70\%-130\% for the lower limit of quantification) were accepted, and the residuals were inspected for homoscedasticity.

P450 Genotyping. Analysis of CYP1A2, CYP2C9, CYP2C19, CYP2D6, CYP3A4, and CYP3A5 variant alleles were performed using Taqman-based realtime polymerase chain reaction assays implemented for routine pharmacogenetic analyses at the Center for Psychopharmacology, Diakonhjemmet Hospital. The following variant alleles were included in this study: CYP1A2: the increased induction allele $* 1 F($ rs 762551$)$; $C Y P 2 C 9$ : the reduced-function alleles *2 (rs1799853) and *3 (rs1057910); CYP2C19: the null alleles *2 (rs4244285), $* 3$ (rs4986893), and *4 (rs28399504), and the gain-of-function allele *17 (rs12248560); CYP2D6: the null alleles *3 (rs35742686), *4 (rs3892097), $* 5$ (whole gene deletion), and $* 6$ (rs5030655), the reduced-function alleles *9 (rs5030656), $* 10(\mathrm{rs} 1065852)$, and $* 41$ (rs28371725), as well as the increasedfunction allele (whole gene duplication); CYP3A4: the reduced-function allele *22 (rs35599367); and CYP3A5: the null allele *3 (rs776746).

Data Analysis. The enzyme kinetic parameters were determined using untransformed data and GraphPad Prism 7 by fitting the reaction velocity versus substrate concentration data to the Michaelis-Menten model (eq. 1) or the substrate inhibition model (eq. 2):

$$
\begin{gathered}
v=\frac{V_{\max } \times S}{K_{\mathrm{m}}+S} \\
v=\frac{V_{\max } \times S}{K_{\mathrm{m}}+S\left[1+\left(S / K_{\mathrm{i}}\right)\right]}
\end{gathered}
$$

where $v$ is the velocity of the reaction; $S$ is the substrate concentration; $V_{\max }$ is the maximum velocity; $K_{\mathrm{m}}$ is the Michaelis constant; and $K_{\mathrm{i}}$ is the inhibitor constant.

Since the incubations were performed with varying concentrations of microsomal protein, the $K_{\mathrm{m}}$ values were adjusted for the fraction of unbound drug in microsomes, which was predicted from the physicochemical properties of the substrates and microsomal protein concentration using the Simcyp prediction tool (https://members.simcyp.com/account/tools/fumic). The unbound intrinsic clearance $\left(\mathrm{CL}_{\mathrm{int}, \mathrm{u}}\right)$ was calculated from the ratio of $V_{\max }$ to the unbound Michaelis constant $\left(K_{\mathrm{m}, \mathrm{u}}\right)$. Correlation coefficients were determined by Spearman rank order correlation analysis and significance levels of differences between groups were determined by Mann-Whitney $U$ test using GraphPad Prism 7.

\section{Results}

P450 Activities in Hepatic and Small Intestinal Microsomes. Patient characteristics and diplotype/likely phenotype distribution for $C Y P 1 A 2, C Y P 2 C 9, C Y P 2 C 19, C Y P 2 D 6, C Y P 3 A 4$, and $C Y P 3 A 5$ are given in Tables 2 and 3 , respectively.
TABLE 2

Patient characteristics, described as median and range or absolute numbers at the

\begin{tabular}{|c|c|c|}
\hline \multirow{2}{*}{ Characteristic } & \multicolumn{2}{|c|}{ Median and Range or Absolute Number } \\
\hline & Female $(n=14)$ & Male $(n=6)$ \\
\hline Age $(\mathrm{yr})$ & $46(27-57)$ & $49(43-53)$ \\
\hline Total body weight $(\mathrm{kg})$ & $118(95-166)$ & $143(123-147)$ \\
\hline Body mass index $\left(\mathrm{kg} / \mathrm{m}^{2}\right)$ & $43(35-63)$ & $45(40-46)$ \\
\hline Waist circumference $(\mathrm{cm})$ & $119(97-142)$ & $134(128-140)$ \\
\hline Hip circumference $(\mathrm{cm})$ & $131(110-179)$ & $127(121-133)$ \\
\hline Systolic blood pressure $(\mathrm{mm} \mathrm{Hg})$ & $120(106-172)$ & $116(103-130)$ \\
\hline Diastolic blood pressure (mm Hg) & $81(71-106)$ & $76(65-81)$ \\
\hline Total cholesterol $(\mathrm{mmol} / \mathrm{l})$ & $3.7(1.9-5.3)$ & $3.3(2.4-4.4)$ \\
\hline $\mathrm{HbA} 1 \mathrm{c}(\mathrm{mmol} / \mathrm{mol})$ & $38(34-45)$ & $38(34-45)$ \\
\hline eGFR (CKD-EPI; $\mathrm{ml} / \mathrm{min} / 1.73 \mathrm{~m}^{2}$ ) & $109(91-125)$ & $110(104-126)$ \\
\hline ASAT (U/l) & $25(15-44)$ & $32(21-48)$ \\
\hline ALAT (U/l) & $31(11-89)$ & $51(17-78)$ \\
\hline ALP (U/1) & $68(27-102)$ & $72(56-110)$ \\
\hline Albumin (g/l) & $40(16-44)$ & $43(38-44)$ \\
\hline hs-CRP (mg/l) & $3.0(1.4-19.0)$ & $5.5(1.8-10.0)$ \\
\hline \multicolumn{3}{|l|}{ Comorbidity } \\
\hline Type 2 diabetes & 3 & 0 \\
\hline Hypertension & 5 & 4 \\
\hline Obstructive sleep apnea & 7 & 6 \\
\hline Asthma & 2 & 2 \\
\hline Cholelithiasis & 4 & 0 \\
\hline Present smoker & 0 & 0 \\
\hline
\end{tabular}
time of biopsy obtainment

ALAT, alanine aminotransferase; ALP, alkaline phosphatase; ASAT, aspartate aminotransferase; eGFR, estimated glomerular filtration rate; HbAlc, glycated hemoglobin; hs-CRP, highsensitivity C-reactive protein.

Activities of CYP2C8, CYP2C9, CYP2D6, and CYP3A were quantified in both HLM and human intestinal microsomes (HIM), while activities of CYP1A2, CYP2B6, and CYP2C19 were only quantifiable in HLM. Enzyme kinetic parameters are summarized in Tables 4 and 5 and representative enzyme kinetic curves are shown in Figs. 1 and 2. Substrate concentration versus velocity curves showed Michaelis-Menten enzyme kinetics, except for the formation of 1-OH-midazolam where the substrate inhibition model was

TABLE 3

Distribution of CYP1A2, CYP2C9, CYP2C19, CYP2D6, CYP3A4, and CYP3A5 diplotypes and likely phenotypes in patients included in the present study

\begin{tabular}{cclrl}
\hline Enzyme & Diplotype & Likely phenotype & $n$ & \multicolumn{1}{c}{ Reference } \\
\hline CYP1A2 & $* 1 / * 1$ & NM & 1 & Thorn et al., 2012; Tian et al., 2019 \\
& $* 1 / * 17$ & Hyperinducer & 9 & \\
& $* 1 F /$ & Hyperinducer & 10 & \\
& $* 1 F$ & & & \\
CYP2C9 & $* 1 / * 1$ & NM & 15 & Caudle et al., 2014 \\
& $* 1 / * 2$ & IM & 5 & \\
CYP2C19 & $* 17 * 17$ & UM & 1 & Moriyama et al., 2017 \\
& $* 1 / * 17$ & RM & 8 & \\
& $* 1 / * 1$ & NM & 5 & \\
& $* 1 / * 2$ & IM & 4 & \\
& $* 2 / * 17$ & IM & 1 & \\
& $* 2 / * 2$ & PM & 1 & \\
CYP2D6 & $* 1 / * 1$ & NM & 8 & Brown et al., 2019 \\
& $* 1 / * 9$ & NM & 2 & \\
& $* 1 / * 41$ & NM & 3 & \\
& $* 1 / * 4$ & IM & 5 & \\
& $* 4 / * 10$ & IM & 1 & \\
CYP3A4 & $* 5 / * 5$ & PM & 1 & \\
CYP3A5 & $* 1 / * 1$ & NM & 20 & \\
& $* 1 / * 3$ & IM & 1 & Birdwell et al., 2015 \\
& $* 3 / * 3$ & PM & 19 & \\
\hline
\end{tabular}

IM, intermediate metabolizer; NM, normal metabolizer; PM, poor metabolizer; RM, rapid metabolizer; UM, ultrarapid metabolizer. 
TABLE 4

Enzyme kinetic parameters (presented as median, range, and maximum/minimum ratio) for metabolite formations representative of CYP1A2, CYP2B6, CYP2C8, CYP2C9, CYP2C19, CYP2D6, and CYP3A activities in human liver microsomes

\begin{tabular}{|c|c|c|c|c|c|c|c|c|c|c|c|c|c|}
\hline \multirow{2}{*}{ Enzyme/Metabolite } & \multirow{2}{*}{$n$} & \multicolumn{4}{|c|}{$V_{\max }(\mathrm{nmol} / \mathrm{min}$ per milligram protein $)$} & \multicolumn{4}{|c|}{$K_{\mathrm{m}, \mathrm{u}}(\mu \mathrm{M})$} & \multicolumn{4}{|c|}{$\begin{array}{c}\mathrm{CL}_{\text {int,u }}(\mu \mathrm{l} / \mathrm{min} \text { per milligram } \\
\text { protein) }\end{array}$} \\
\hline & & Median & Max & Min & Max/Min & Median & Max & Min & Max/Min & Median & Max & Min & Max/Min \\
\hline CYP1A2/paracetamol & 20 & 0.201 & 0.329 & 0.048 & 7 & 52 & 575 & 17 & 34 & 2.1 & 8.6 & 0.6 & 15 \\
\hline CYP2B6/OH-bupropion & 20 & 0.067 & 0.445 & 0.016 & 28 & 47 & 189 & 20 & 9 & 1.4 & 11.9 & 0.5 & 23 \\
\hline CYP2C $8 / N$-desethylamodiaquine & 20 & 0.523 & 0.963 & 0.123 & 8 & 4 & 13 & 1 & 12 & 108 & 604 & 31 & 19 \\
\hline CYP2C9/4-OH-diclofenac & 20 & 1.054 & 1.865 & 0.392 & 5 & 25 & 68 & 10 & 7 & 39 & 140 & 6 & 22 \\
\hline CYP2C19/4-OH-mephenytoin & 13 & 0.030 & 0.092 & 0.010 & 9 & 32 & 107 & 8 & 14 & 1.3 & 2.9 & 0.2 & 17 \\
\hline CYP2D6/1-OH-bufuralol & 20 & 0.012 & 0.038 & 0.005 & 8 & 24 & 56 & 10 & 6 & 0.5 & 1.6 & 0.1 & 14 \\
\hline CYP3A/1-OH-midazolam & 20 & 0.164 & 0.534 & 0.073 & 7 & 4 & 7 & 3 & 3 & 39 & 126 & 14 & 9 \\
\hline
\end{tabular}

Max, maximum; Max/Min, maximum/minimum; Min, minimum

used. Due to small liver tissue amounts and/or low enzyme activity, 4-OH-mephenytoin formation (CYP2C19) was only quantifiable in 13 of 20 individual HLM.

The $\mathrm{CL}_{\mathrm{int}, \mathrm{u}}$ values were overall higher in the liver compared with the small intestine, with median HLM/HIM ratios of five (CYP2D6), 16 (CYP2C9), and 252 (CYP2C8) (Table 6). However, the CYP3A activities in HLM and HIM were comparable, with a median $\mathrm{CL}_{\mathrm{int}, \mathrm{u}}$ HLM/HIM ratio of 1.5 (Table 6). While the median ratio of $K_{\mathrm{m}, \mathrm{u}}$ values in HLM and HIM was between 0.5 and 1.4 for all P450 enzymes investigated, the $V_{\max }$ values showed a larger interorgan difference with median HLM/HIM ratios ranging from 2 (CYP3A) to 196 (CYP2C8) (Table 6).

Both the $V_{\max }$ and $K_{\mathrm{m}, \mathrm{u}}$ values showed large variability between patients, resulting in considerable interindividual variability in $\mathrm{CL}_{\mathrm{int}, \mathrm{u}}$ values ranging from 9-fold (CYP3A) to 23-fold (CYP2B6) in HLM and from 5-fold (CYP2D6) to 55-fold (CYP2C9) in HIM (Tables 4 and 5).

Hepatic $\mathrm{CL}_{\text {int,u }}$ values for the CYP1A2-mediated reaction were significantly higher in patients with the $* 1 / * 1 F$ diplotype compared with the $* 1 F / * 1 F$ diplotype $(P<0.05)$ (Fig. 3). This was accompanied by significantly lower $K_{\mathrm{m}, \mathrm{u}}$ values in the $* 1 / * 1 F$ group $(P<0.05)$, while no difference in $V_{\max }$ values was detected $(P>0.05)$ (Supplemental Fig. 1). Unbound intrinsic clearance values for the reactions mediated by CYP2C9, CYP2C19, or CYP2D6 were not significantly affected by diplotype or likely phenotype in HLM or HIM (Fig. 3). The impact of CYP3A5 diplotype on unbound intrinsic clearance for the CYP3Amediated reaction could not be investigated since the $C Y P 3 A 5^{*} 1$ allele was present in only one patient.

Interorgan Correlation of $\mathbf{P 4 5 0}$ Activities. A positive correlation ( $r=0.74, P<0.001)$ was found between the intestinal and hepatic microsomal $\mathrm{CL}_{\mathrm{int}, \mathrm{u}}$ values for the formation of 4-OH-diclofenac (CYP2C9) (Fig. 4). There were no significant correlations between
$\mathrm{CL}_{\text {int,u }}$ values in HLM and HIM for the probe reactions of CYP2C8, CYP2D6, or CYP3A (Fig. 4).

Intraorgan Correlation of $\mathbf{P 4 5 0}$ Activities. Positive correlations were found between $\mathrm{CL}_{\text {int,u }}$ values of reactions mediated by several different P450 isoforms in the HLM. The activity of CYP1A2 correlated positively with CYP2B6 ( $r=0.51)$, CYP2D6 ( $r=0.58)$, and CYP3A $(r=0.68)$ activities (Table 7). Also, hepatic CYP2B6 activity was positively correlated with CYP2D6 $(r=0.60)$ and CYP3A $(r=0.67)$ activities (Table 7). There was a positive correlation between CYP2D6 and CYP3A activities in both HLM $(r=0.47)$ (Table 7) and HIM $(r=0.65)$ (Table 8). Furthermore, in HIM the activity of CYP2C8 correlated positively with CYP2C9 $(r=0.53)$, CYP2D6 $(r=0.50)$, and CYP3A $(r=0.64)$ activities (Table 8$)$.

Correlation between BMI and P450 Activities. There was a negative correlation between patient BMI and hepatic $\mathrm{CL}_{\mathrm{int}, \mathrm{u}}$ values for the CYP2B6-mediated formation of OH-bupropion $(r=-0.72$, $P<0.001$ ) (Fig. 5). No significant correlations were observed between BMI and the other hepatic P450 activities or between BMI and the intestinal $\mathrm{P} 450$ activities (data not shown).

Sex Differences in $\mathbf{P 4 5 0}$ Activities. The small intestinal $\mathrm{CL}_{\mathrm{int}, \mathrm{u}}$ values for the CYP3A-mediated reaction were significantly higher in the female individuals (median of $33 \mu \mathrm{l} / \mathrm{min}$ per milligram protein) compared with the male individuals (median of $18 \mu \mathrm{l} / \mathrm{min}$ per milligram protein; $P<0.05$ ) (Fig. 6). No difference in hepatic CYP3A activity between sexes was detected $(P>0.05)$ (Fig. 6). No differences between sexes were observed for hepatic or intestinal activities of the other P450 enzymes (data not shown).

\section{Discussion}

Data on hepatic and intestinal P450 metabolism is relevant with respect to evaluation of susceptibility to drug-drug interactions,

TABLE 5

Enzyme kinetic parameters (presented as median, range, and maximum/minimum ratio) for metabolite formations representative of CYP2C8, CYP2C9, CYP2D6, and CYP3A activities in human intestinal microsomes

\begin{tabular}{|c|c|c|c|c|c|c|c|c|c|c|c|c|c|}
\hline \multirow{2}{*}{ Enzyme/Metabolite } & \multirow{2}{*}{$n$} & \multicolumn{4}{|c|}{$V_{\max }(\mathrm{nmol} /$ min per milligram protein $)$} & \multicolumn{4}{|c|}{$K_{\mathrm{m}, \mathrm{u}}(\mu \mathrm{M})$} & \multicolumn{4}{|c|}{$\begin{array}{c}\mathrm{CL}_{\text {int,u }}(\mu \mathrm{l} / \mathrm{min} \text { per milligram } \\
\text { protein) }\end{array}$} \\
\hline & & Median & $\operatorname{Max}$ & Min & Max/Min & Median & $\operatorname{Max}$ & Min & Max/Min & Median & Max & Min & Max/Min \\
\hline CYP1A2/paracetamol & 20 & - & - & - & - & - & - & - & - & - & - & - & - \\
\hline CYP2B6/OH-bupropion & 20 & - & - & - & - & - & - & - & - & - & - & - & - \\
\hline CYP2C $8 / N$-desethylamodiaquine & 20 & 0.003 & 0.007 & 0.001 & 5 & 6 & 10 & 2 & 6 & 0.5 & 2.1 & 0.2 & 11 \\
\hline CYP2C9/4-OH-diclofenac & 20 & 0.056 & 0.213 & 0.008 & 26 & 17 & 59 & 2 & 38 & 2.9 & 17.1 & 0.3 & 55 \\
\hline CYP2C19/4-OH-mephenytoin & 20 & - & - & - & - & - & - & - & - & - & - & - & - \\
\hline CYP2D6/1-OH-bufuralol & 20 & 0.004 & 0.009 & 0.003 & 3 & 48 & 70 & 33 & 2 & 0.09 & 0.20 & 0.04 & 5 \\
\hline CYP3A/1-OH-midazolam & 20 & 0.090 & 0.237 & 0.034 & 7 & 3 & 6 & 2 & 2 & 31 & 59 & 8 & 7 \\
\hline
\end{tabular}

Max, maximum; Max/Min, maximum/minimum; Min, minimum; - , no detectable activity. 
CYP1A2

Phenacetin O-deethylation

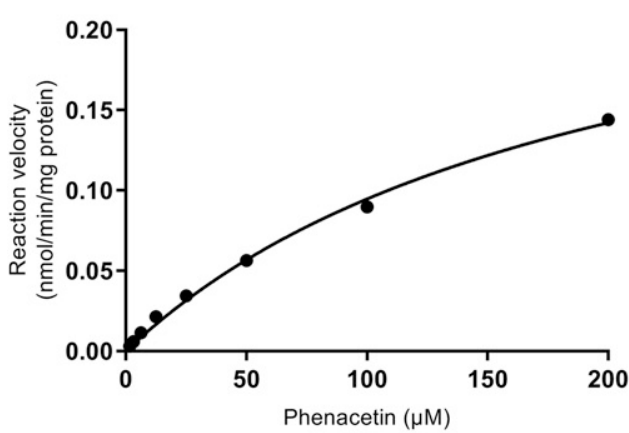

CYP2C8

Amodiaquine $\mathrm{N}$-deethylation *

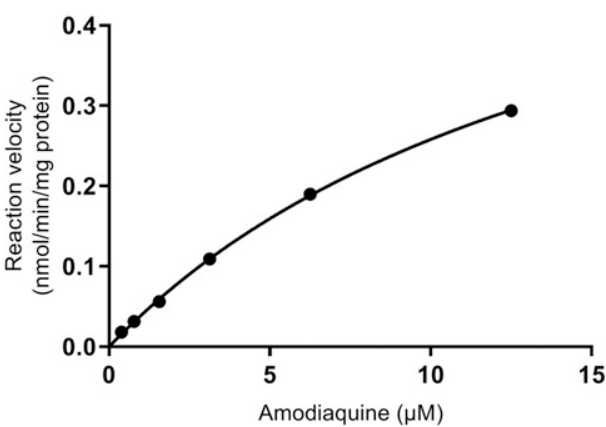

CYP2C19

S-Mephenytoin 4-hydroxylation

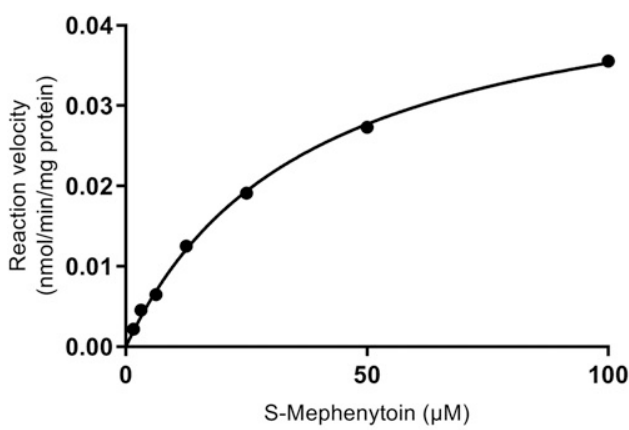

CYP2B6

Bupropion hydroxylation

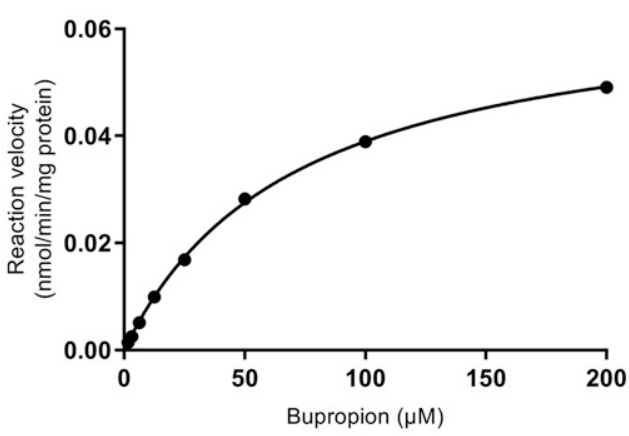

CYP2C9

Diclofenac 4-hydroxylation

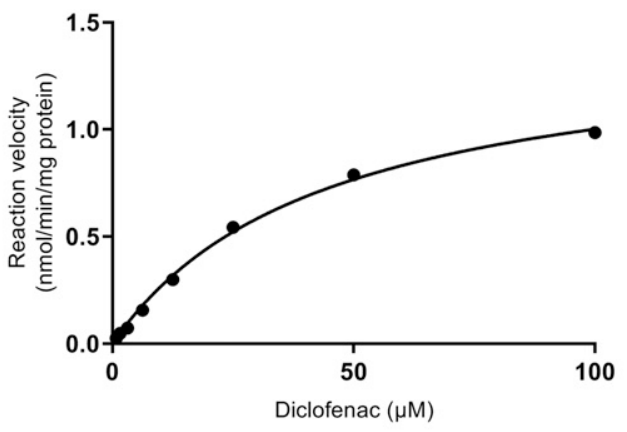

CYP2D6

Bufuralol 1-hydroxylation

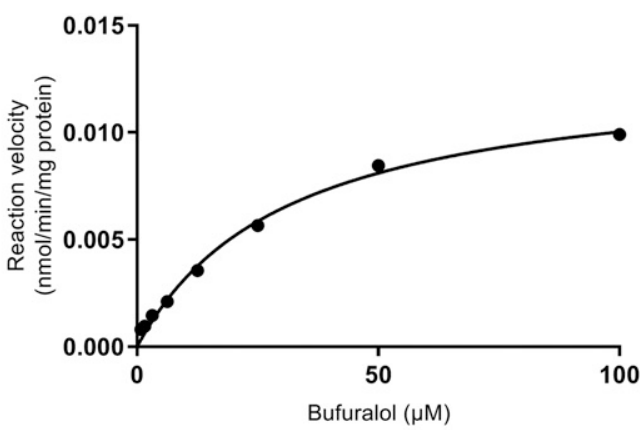

CYP3A

Midazolam 1-hydroxylation

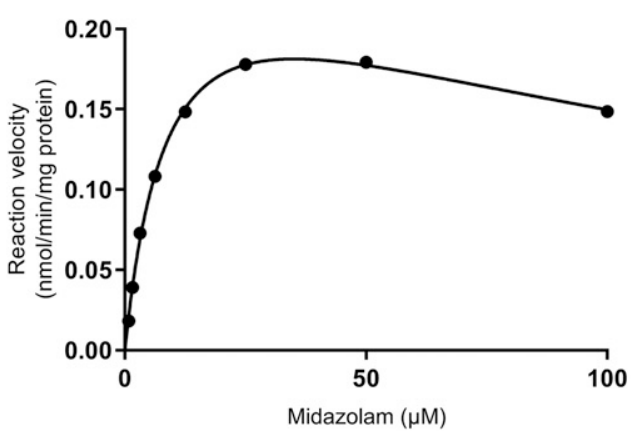

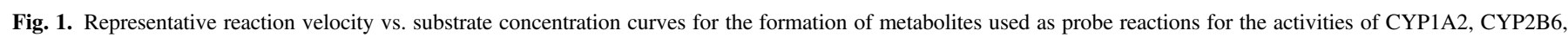

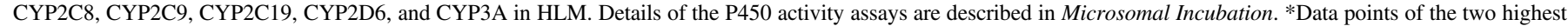
substrate concentrations were excluded due to sharp drops in the curves for which the reason is unknown. 


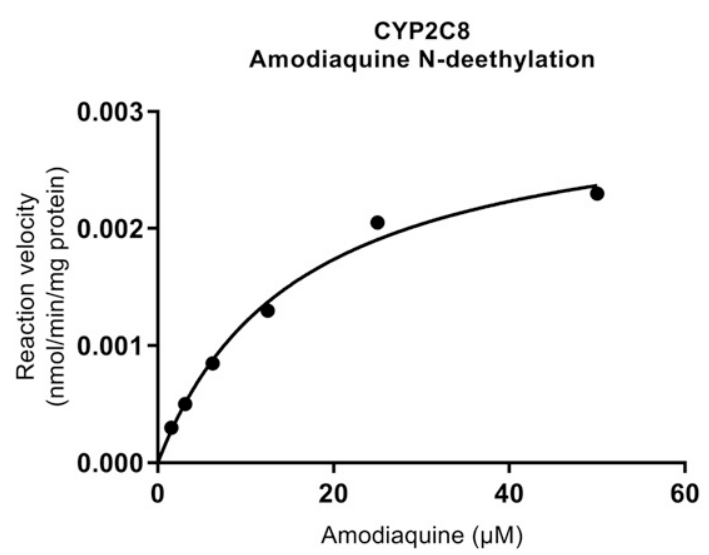

CYP2D6

Bufuralol 1-hydroxylation

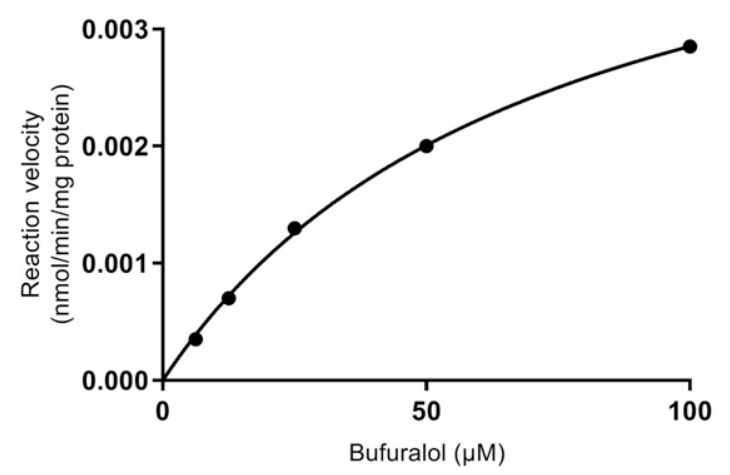

CYP2C9

Diclofenac 4-hydroxylation

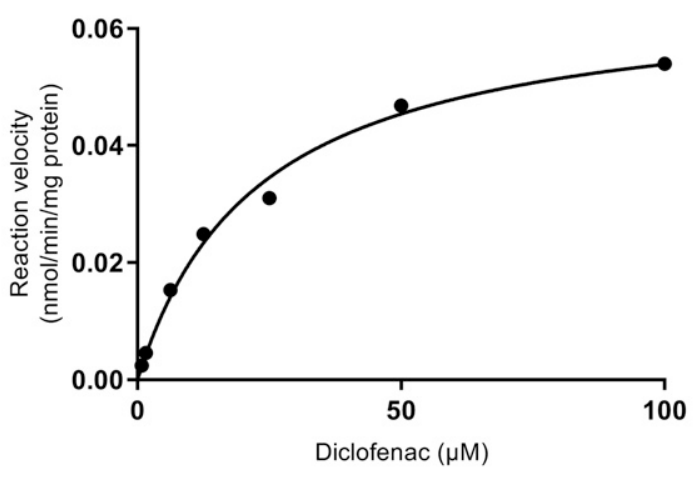

CYP3A

Midazolam 1-hydroxylation

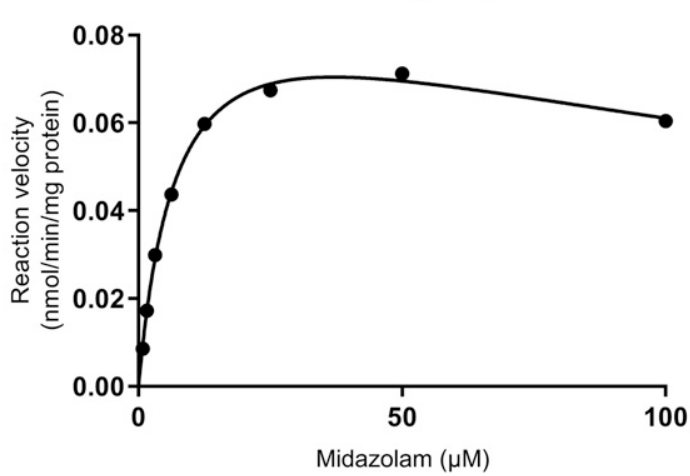

Fig. 2. Representative reaction velocity vs. substrate concentration curves for the formation of metabolites used as probe reactions for the activities of $\mathrm{CYP} 2 \mathrm{C} 8$, $\mathrm{CYP} 2 \mathrm{C} 9$, CYP2D6, and CYP3A in HIM. Details of the P450 activity assays are described in Microsomal Incubation.

assessment of oral bioavailability in drug development, and prediction of drug disposition in different patient populations. To our knowledge, this is the first study to investigate the activities of drug metabolizing P450 enzymes in microsomes prepared from paired liver and small intestinal biopsies from patients with obesity.

Considerable interindividual variability in both hepatic (up to 23-fold) and intestinal (up to 55-fold) unbound intrinsic clearance values of $\mathrm{P} 450$ probe reactions was observed in the present study. While P450 activities have been mostly investigated in pooled microsomal preparations, large variability in enzyme kinetic parameters has also been reported in a limited number of studies in individual HLM and HIM from other patient populations (Paine et al., 1997; Madani et al., 1999; Obach et al., 2001; Yang et al., 2012; Gao et al., 2016; Clermont et al., 2019). Hepatic intrinsic clearance values of the investigated $\mathrm{P} 450$ probes in this study were mostly in the lower end of the range of those reported in another study in Caucasians (Yang et al., 2012). Similarly, intestinal intrinsic clearance values for the CYP3A-mediated reaction were within or slightly lower than the ranges previously reported in individual jejunal microsomes (Paine et al., 1997; Clermont et al., 2019). To what extent these moderately lower activities are related to the specific patient population investigated is difficult to evaluate since some variation across studies may also be due to methodological factors. Furthermore, an overall lower interindividual variability in P450 activities in both tissues was found in the current study, which could possibly be explained by this study being performed in a more homogenous patient group. Interestingly, the CYP1A2 diplotype significantly affected the activity of CYP1A2 in HLM, while activities of the other P450 enzymes were not affected by diplotype or likely phenotype. However, the number of samples analyzed may have been too low to disclose differences between genotypes.

As expected, the microsomal $\mathrm{P} 450$ activities were overall considerably higher in the liver compared with the small intestine. However, the ratios showed large variability, suggesting that the contribution of the small intestine to the first pass metabolism of CYP2D6 and CYP2C9 substrates could vary considerably between individuals. For CYP2C8, the intestinal activities were negligible compared with the hepatic activities, in line with a previous study comparing pooled HLM and HIM (Misaka et al., 2013). On the contrary, microsomal CYP3A activities were comparable with a 1.5 -fold higher median $\mathrm{CL}_{\mathrm{int}, \mathrm{u}}$ value in HLM compared with HIM. This is in agreement with

\section{TABLE 6}

Ratios of enzyme kinetic parameters for the probe reactions of CYP2C8, CYP2C9, CYP2D6, and CYP3A in individual HLM and HIM presented as median and range

\begin{tabular}{|c|c|c|c|c|}
\hline \multirow{2}{*}{ Enzyme/Metabolite } & \multirow{2}{*}{$n$} & \multicolumn{3}{|c|}{ Ratio HLM/HIM } \\
\hline & & $V_{\max }$ & $K_{\mathrm{m}, \mathrm{u}}$ & $\mathrm{CL}_{\mathrm{int}, \mathrm{u}}$ \\
\hline $\begin{array}{l}\text { CYP2C8/ } \\
N \text {-desethylamodiaquine }\end{array}$ & 20 & $196(22-410)$ & $0.8(0.1-4.0)$ & $252(40-1544)$ \\
\hline CYP2C9/4-OH-diclofenac & 20 & $23(5-67)$ & $1.4(0.9-14.5)$ & $16(4-26)$ \\
\hline CYP2D6/1-OH-bufuralol & 20 & $3.2(1.0-6.0)$ & $0.5(0.2-1.6)$ & $4.6(1.7-22.8)$ \\
\hline CYP3A/1-OH-midazolam & 20 & $2.3(0.4-4.9)$ & $1.4(0.7-2.2)$ & $1.5(0.4-4.4)$ \\
\hline
\end{tabular}




\section{HLM}

CYP1A2

Phenacetin O-deethylation

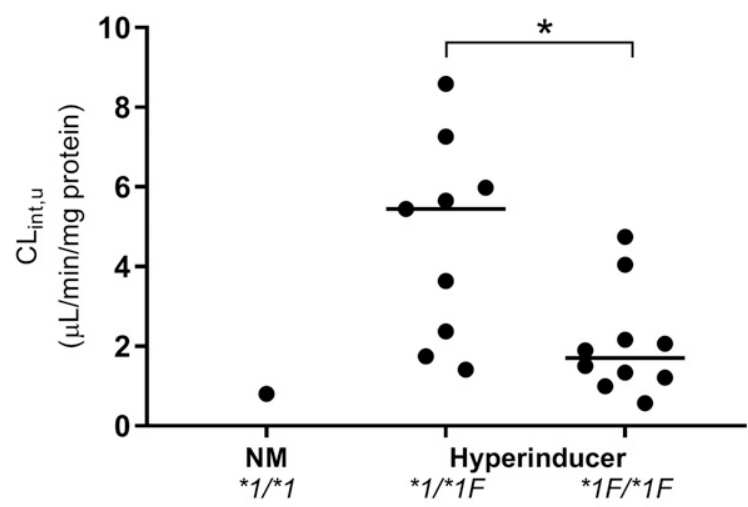

CYP2C19

S-Mephenytoin 4-hydroxylation



CYP2C9

Diclofenac 4-hydroxylation

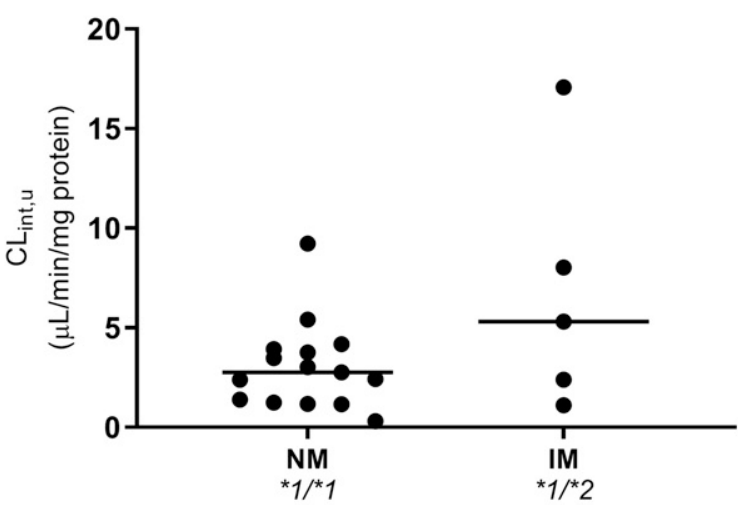

CYP2C9

Diclofenac 4-hydroxylation

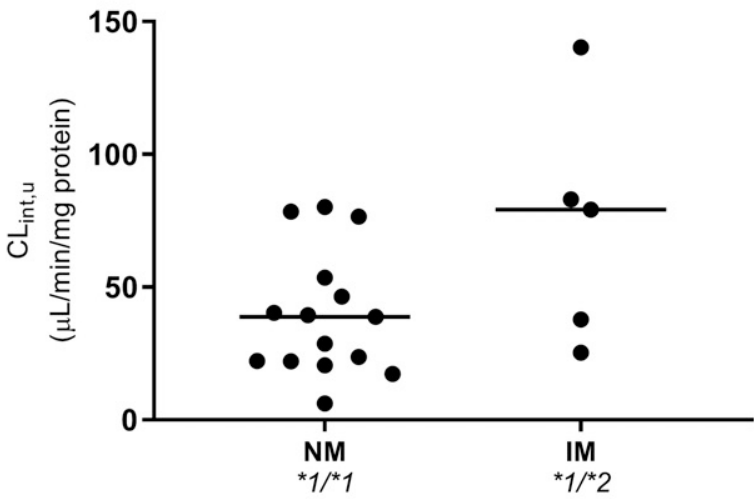

CYP2D6

Bufuralol 1-hydroxylation

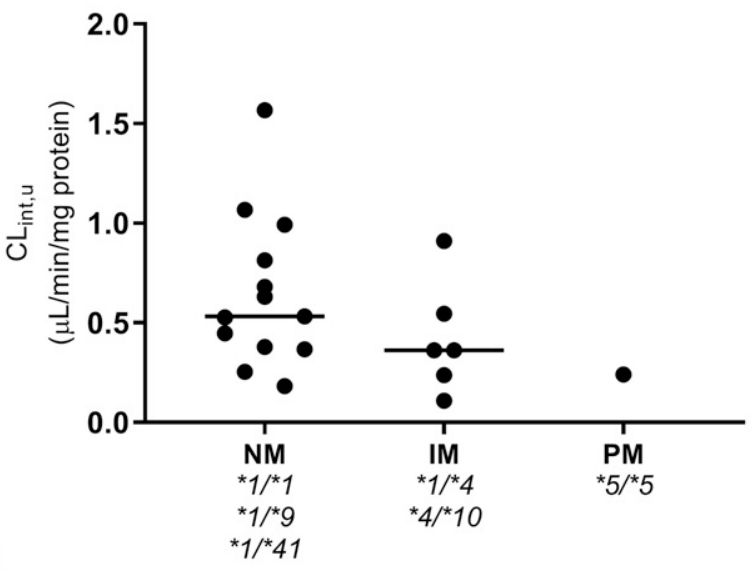

CYP2D6

Bufuralol 1-hydroxylation

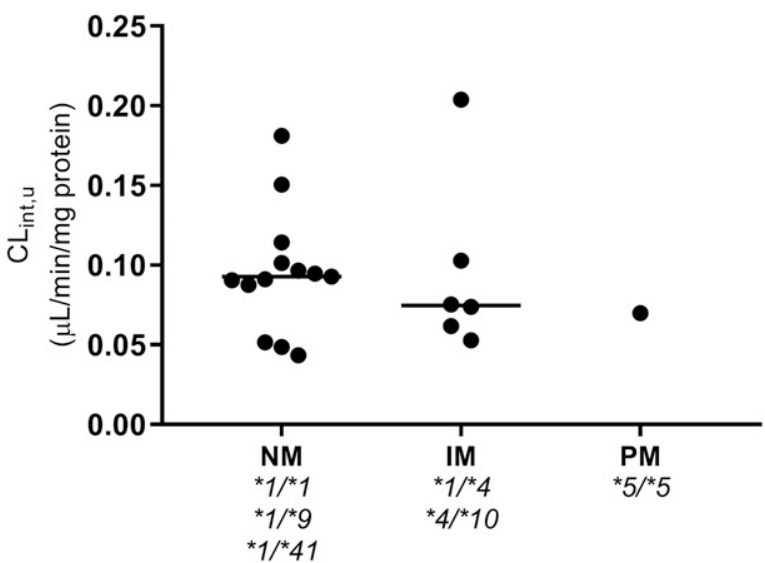

Fig. 3. The $\mathrm{CL}_{\text {int,u }}$ values for the reactions mediated by CYP1A2, CYP2C9, CYP2C19, and CYP2D6 in HLM and by CYP2C9 and CYP2D6 in HIM grouped by the respective P450 diplotype or likely phenotype. The lines represent the median in each group. *Difference between groups was statistically significant $(P<0.05)$. IM, intermediate metabolizer; NM, normal metabolizer; PM, poor metabolizer; RM, rapid metabolizer; UM, ultrarapid metabolizer. 
CYP2C8

Amodiaquine $\mathrm{N}$-deethylation

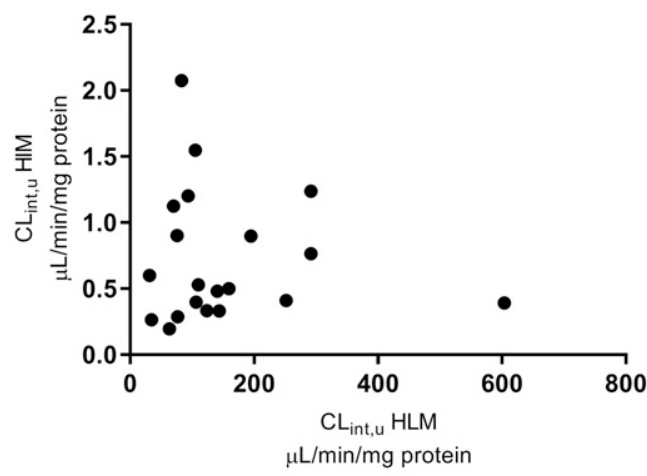

CYP2D6

Bufuralol 1-hydroxylation

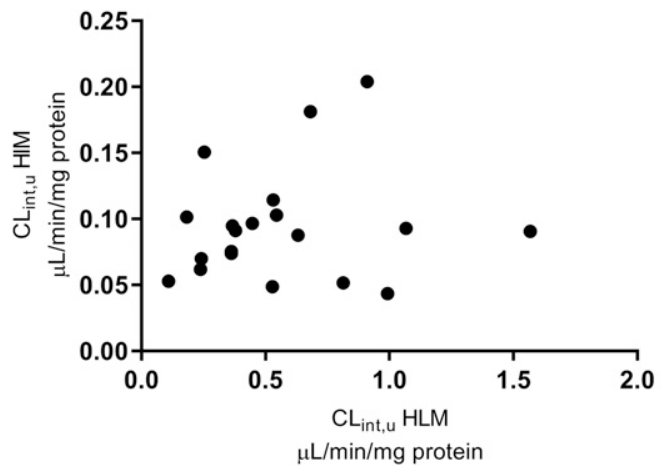

CYP2C9

Diclofenac 4-hydroxylation



CYP3A

Midazolam 1-hydroxylation




1-hydroxylation (CYP2D6), and midazolam 1-hydroxylation (CYP3A) in individual patients. Dotted linear trend line added for visualization purposes.

the ratio between hepatic and jejunal microsomal CYP3A activities reported in paired samples by Paine et al. (1997), as well as with recent studies in subjects both with and without obesity finding comparable mRNA and protein content of CYP3A4 in paired liver and jejunum samples (Drozdzik et al., 2018; Lloret-Linares et al., 2019). This underlines the likely important role of the small intestine in the first pass metabolism of CYP3A substrates also in this patient population.

A positive correlation between CYP2C9 activities in HLM and HIM was found. This is in line with a study reporting a borderline significant positive correlation between the intrinsic clearance values for the 4-hydroxylation of diclofenac in hepatic and intestinal homogenates (Läpple et al., 2003), as well as with a recent study in patients with obesity showing a positive correlation between expression levels of CYP2C9 in hepatic and jejunal microsomes (Lloret-Linares

TABLE 7

Correlation coefficients (Spearman's rho) between the $\mathrm{CL}_{\text {int,u }}$ values of P450 isoforms in human liver microsomes

\begin{tabular}{lccrrrr}
\hline & CYP1A2 & CYP2B6 & CYP2C8 & CYP2C9 & CYP2C19 & CYP2D6 \\
\hline CYP2B6 & $0.51^{*}$ & & & & & \\
CYP2C8 & 0.09 & 0.13 & & & & \\
CYP2C9 & -0.22 & -0.07 & 0.32 & & & \\
CYP2C19 & 0.02 & 0.24 & -0.55 & 0.02 & & \\
CYP2D6 & $0.58^{* *}$ & $0.60 * *$ & 0.25 & -0.26 & -0.30 & \\
CYP3A & $0.68^{* * *}$ & $0.67 * *$ & 0.36 & -0.15 & -0.36 & $0.47 *$ \\
\hline
\end{tabular}

${ }^{*} P<0.05 ; * * P<0.01 ; * * * P<0.001$. et al., 2019). It could be speculated that this is partly explained by the activity of CYP2C9 being largely influenced by genetics (Zanger and Schwab, 2013); however, interestingly no correlation was found between hepatic and intestinal activities of the highly polymorphic enzyme CYP2D6. Also, no interorgan correlation was present for the activities of CYP2C8 and CYP3A, which is in agreement with other studies (Lown et al., 1994; Paine et al., 1997; Lin et al., 2002; Läpple et al., 2003; von Richter et al., 2004). The lack of interorgan associations may be related to tissue-specific regulation due to both differential expression patterns of $\mathrm{P} 450$ regulating transcription factors in the small intestine and liver, as well as exposure to different endogenous and environmental factors (Pavek and Dvorak, 2008). For CYP3A4, the vitamin D receptor has been shown to be an important nuclear receptor involved in inducible transcriptional regulation of CYP3A4 in the intestine, but not in the liver (Matsubara et al., 2008; Khan et al., 2010; Thirumaran et al., 2012). Furthermore, positive correlations between activities of

TABLE 8

Correlation coefficients (Spearman's rho) between the $\mathrm{CL}_{\mathrm{int}, \mathrm{u}}$ values of $\mathrm{P} 450$ isoforms in human intestinal microsomes

\begin{tabular}{llll}
\hline & CYP2C 8 & CYP2C9 & CYP2D6 \\
\hline CYP2C9 & $0.53^{*}$ & & \\
CYP2D6 & $0.50^{*}$ & 0.00 & \\
CYP3A & $0.64 * *$ & 0.22 & $0.65^{* *}$ \\
\hline
\end{tabular}

${ }^{*} P<0.05 ; * * P<0.01$. 


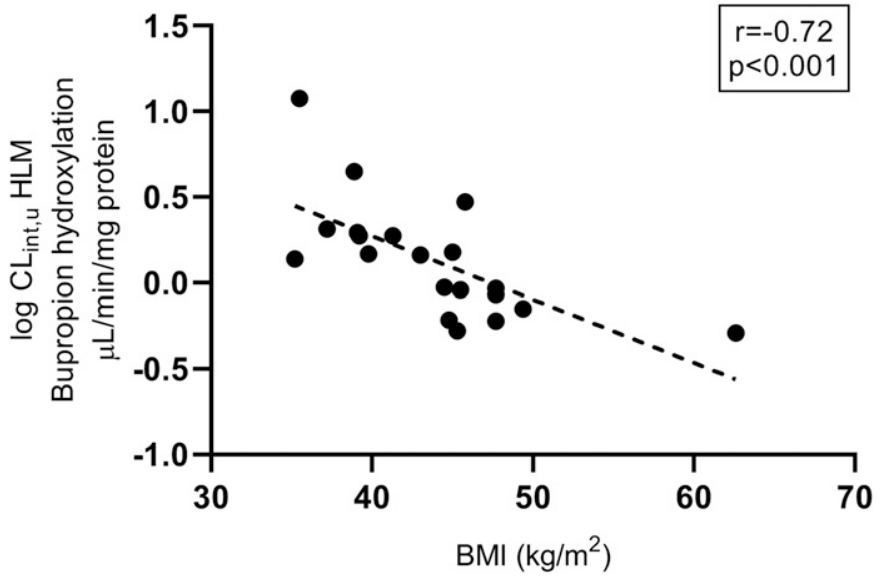

Fig. 5. Correlation between $B M I$ and $\mathrm{CL}_{\text {int,u }}$ values for the bupropion hydroxylation (CYP2B6) in HLM. For visualization purposes, the $y$-axis has been logarithmically transformed and a dotted linear trend line has been added.

different P450 isoforms were found in both HLM and HIM in the present study. This is in line with other studies of expression and activity of P450 enzymes in human liver samples (Wortham et al., 2007; Yang et al., 2010, 2012; Gao et al., 2016), while limited data currently exist on the association between P450 isoforms in the human intestine (Obach et al., 2001; Lindell et al., 2003). Intraorgan correlations of $\mathrm{P} 450$ activities may in part be explained by shared regulatory pathways within the liver and intestine since the expression of some $\mathrm{P} 450$ isoforms is regulated by common transcription factors (Wortham et al., 2007; Manikandan and Nagini, 2018). Also, post-transcriptional coregulation of enzyme activities may occur via NADPH-cytochrome P450 oxidoreductase and cytochrome $b_{5}$ (Wortham et al., 2007; Zhang et al., 2015, 2016).

Interestingly, the present study showed significantly higher $\mathrm{CL}_{\mathrm{int}, \mathrm{u}}$ for the 1-hydroxylation of midazolam in individual HIM from females compared with males. In agreement with this, increased oral clearance of CYP3A substrates and higher small intestinal CYP3A activity have been reported in females compared with males (Lown et al., 1994; Lampen et al., 1996; Kang et al., 2003; Chen et al., 2006). However, a recent study of P450 expression in jejunum from patients with severe obesity found no sex differences (Miyauchi et al., 2016). Findings in human liver samples have been conflicting (Hunt et al., 1992; Shimada et al., 1994; George et al., 1995; Wolbold et al., 2003), and in the current study no difference in hepatic CYP3A activities between sexes was detected. Our observations could suggest higher CYP3A activity in the small intestine, but not in the liver, of female compared with male individuals with obesity. However, given the low sample size, and especially the low number of male subjects, this needs to be validated in a larger study.

In the present study, we found a negative correlation between BMI and hepatic CYP2B6 activity in patients with obesity, which has to the authors' knowledge not been previously reported. It is difficult to comment on the possible mechanisms behind this finding. In general, it could be speculated that reductions in P450 activity with increasing weight are related to inflammation status since inflammatory cytokines have been found to alter the expression and activity of various P450 enzymes in hepatocytes and/or HepaRG cells (Aitken and Morgan, 2007; Rubin et al., 2015). However, no correlation between BMI and activity was found for the other P450 enzymes investigated. Furthermore, it must be emphasized that the validity of this finding is challenged by the low sample size. Further studies in individuals ranging from normal weight to severe obesity are required to elucidate the effect of obesity on drug metabolizing P450 enzymes in the liver.

This study has some limitations. While microsomes are the most commonly used matrix for studying drug metabolism in vitro, this approach has some drawbacks. The preparation of microsomes through subcellular fractionation has been associated with both loss of microsomal protein and contamination of the microsomal fraction with nonmicrosomal proteins (Wegler et al., 2017). We did not account for this through the use of a microsomal protein marker. Also, the intestinal samples were homogenized directly without prior mucosal scraping or enterocyte elution. Thus, the homogenates used to prepare microsomal fractions did not exclusively contain mature enterocytes in which the P450 enzymes are concentrated. (Galetin and Houston, 2006; Hatley et al., 2017). Furthermore, an important challenge associated with studying human biopsies is that the observations in a small tissue sample may not be representative of the whole organ, thereby complicating in vitro-in vivo extrapolation. This is particularly relevant in intestinal biopsies, given the heterogeneity of the gastrointestinal tract. Therefore, it should be emphasized that the P450 activities in the present study were estimated per milligram of microsomal protein, and scaling up to whole organ activities was necessary to fully compare the P450 metabolism in these two tissues. It should also be noted that the patients were subjected to a 3-week lowenergy diet prior to biopsy harvesting, which has been shown to significantly reduce liver volume and intrahepatic fat (Edholm et al., 2011). Therefore, the data presented may not be fully transferrable to patients with untreated severe obesity. Finally, it must be emphasized that no a priori power calculation was performed and that the study population was relatively small.

In conclusion, the data on $\mathrm{P} 450$ activities in paired liver and small intestinal samples presented in the current study may be useful in the modeling and prediction of drug disposition in patients with obesity.
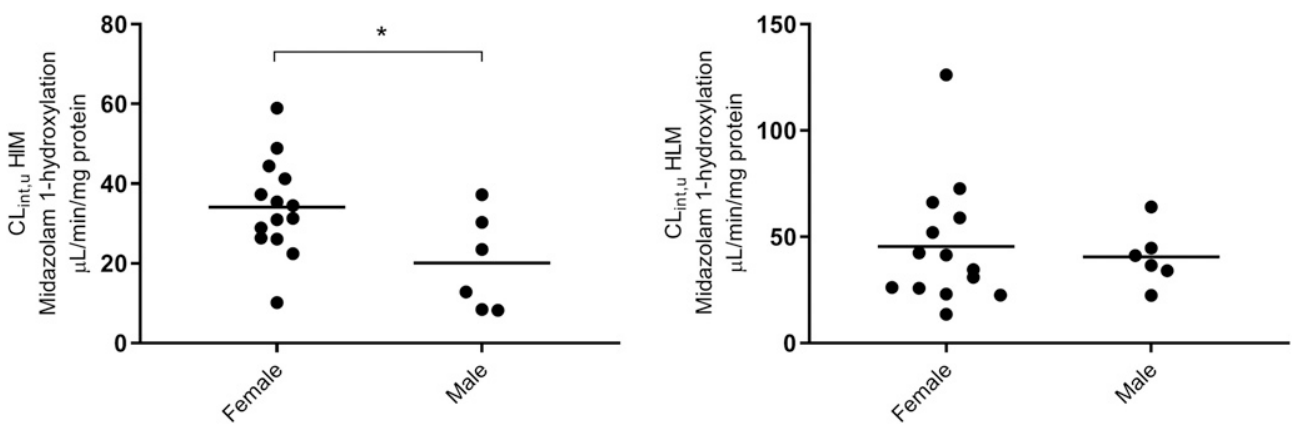

Fig. 6. The $\mathrm{CL}_{\text {intu }}$ values for the 1-hydroxylation of midazolam (CYP3A, $\mu 1 / \mathrm{min}$ per milligram protein) in HIM and HLM from females and males. The lines represent the median in each group. *Difference between males and females was statistically significant $(P<0.05)$. 


\section{Acknowledgments}

We express our gratitude to the participants, surgical staff, and study personnel in the COCKTAIL study.

\section{Authorship Contributions}

Participated in research design: Krogstad, Peric, Robertsen, Kringen, Wegler, Hjelmesæth, Karlsson, S. Andersson, Artursson, Åsberg, T. B. Andersson, Christensen.

Conducted experiments: Krogstad, Peric, Kringen, Angeles.

Contributed new reagents or analytic tools: Peric, T. B. Andersson.

Performed data analysis: Krogstad, Peric, Robertsen, T. B. Andersson, Christensen.

Wrote or contributed to the writing of the manuscript: Krogstad, Peric, Robertsen, Kringen, Wegler, Angeles, Hjelmesæth, Karlsson, S. Andersson, Artursson, Åsberg, T. B. Andersson, Christensen.

\section{References}

Achour B, Barber J, and Rostami-Hodjegan A (2014) Expression of hepatic drug-metabolizing cytochrome P450 enzymes and their intercorrelations: a meta-analysis. Drug Metab Dispos 42:1349-1356. Aitken AE and Morgan ET (2007) Gene-specific effects of inflammatory cytokines on cytochrome P450 2C, 2B6 and 3A4 mRNA levels in human hepatocytes. Drug Metab Dispos 35:1687-1693.

Birdwell KA, Decker B, Barbarino JM, Peterson JF, Stein CM, Sadee W, Wang D, Vinks AA, He Y, Swen JJ, et al. (2015) Clinical Pharmacogenetics Implementation Consortium (CPIC) guidelines for CYP3A5 genotype and tacrolimus dosing. Clin Pharmacol Ther 98:19-24.

Bradford MM (1976) A rapid and sensitive method for the quantitation of microgram quantities of protein utilizing the principle of protein-dye binding. Anal Biochem 72:248-254.

Brill MJ, Diepstraten J, van Rongen A, van Kralingen S, van den Anker JN, and Knibbe CA (2012) Impact of obesity on drug metabolism and elimination in adults and children. Clin Pharmacokinet 51:277-304.

Brown JT, Bishop JR, Sangkuhl K, Nurmi EL, Mueller DJ, Dinh JC, Gaedigk A, Klein TE, Caudle KE, McCracken JT, et al. (2019) Clinical Pharmacogenetics Implementation Consortium guideline for cytochrome P450 (CYP)2D6 genotype and atomoxetine therapy. Clin Pharmacol Ther 106:94-102.

Caudle KE, Rettie AE, Whirl-Carrillo M, Smith LH, Mintzer S, Lee MT, Klein TE, and Callaghan JT; Clinical Pharmacogenetics Implementation Consortium (2014) Clinical Pharmacogenetics Implementation Consortium guidelines for $C Y P 2 C 9$ and $H L A-B$ genotypes and phenytoin dosing. Clin Pharmacol Ther 96:542-548.

Chen M, Ma L, Drusano GL, Bertino JS Jr, and Nafziger AN (2006) Sex differences in CYP3A activity using intravenous and oral midazolam. Clin Pharmacol Ther 80:531-538.

Clermont V, Grangeon A, Barama A, Turgeon J, Lallier M, Malaise J, and Michaud V (2019) Activity and mRNA expression levels of selected cytochromes P450 in various sections of the human small intestine. Br J Clin Pharmacol 85:1367-1377.

Drozdzik M, Busch D, Lapczuk J, Müller J, Ostrowski M, Kurzawski M, and Oswald S (2018) Protein abundance of clinically relevant drug-metabolizing enzymes in the human liver and intestine: a comparative analysis in paired tissue specimens. Clin Pharmacol Ther 104:515-524.

Edholm D, Kullberg J, Haenni A, Karlsson FA, Ahlström A, Hedberg J, Ahlström H, and Sundbom M (2011) Preoperative 4-week low-calorie diet reduces liver volume and intrahepatic fat, and facilitates laparoscopic gastric bypass in morbidly obese. Obes Surg 21:345-350.

Galetin A and Houston JB (2006) Intestinal and hepatic metabolic activity of five cytochrome P450 enzymes: impact on prediction of first-pass metabolism. J Pharmacol Exp Ther 318:1220-1229.

Gao N, Tian X, Fang Y, Zhou J, Zhang H, Wen Q, Jia L, Gao J, Sun B, Wei J, et al. (2016) Gene polymorphisms and contents of cytochrome P450s have only limited effects on metabolic activities in human liver microsomes. Eur J Pharm Sci 92:86-97.

George J, Byth K, and Farrell GC (1995) Age but not gender selectively affects expression of individual cytochrome P450 proteins in human liver. Biochem Pharmacol 50:727-730.

Hatley OJ, Jones CR, Galetin A, and Rostami-Hodjegan A (2017) Quantifying gut wall metabolism: methodology matters. Biopharm Drug Dispos 38:155-160.

Hjelmesæth J, Åsberg A, Andersson S, Sandbu R, Robertsen I, Johnson LK, Angeles PC, Hertel JK Skovlund E, Heijer M, et al. (2018) Impact of body weight, low energy diet and gastric bypass on drug bioavailability, cardiovascular risk factors and metabolic biomarkers: protocol for an open, non-randomised, three-armed single centre study (COCKTAIL). BMJ Open 8:e21878.

Hunt CM, Westerkam WR, and Stave GM (1992) Effect of age and gender on the activity of human hepatic CYP3A. Biochem Pharmacol 44:275-283.

Ingelman-Sundberg M (2005) The human genome project and novel aspects of cytochrome P450 research. Toxicol Appl Pharmacol 207 (Suppl):52-56.

Kang D, Verotta D, Krecic-Shepard ME, Modi NB, Gupta SK, and Schwartz JB (2003) Population analyses of sustained-release verapamil in patients: effects of sex, race, and smoking. Clin Pharmacol Ther 73:31-40.

Khan AA, Dragt BS, Porte RJ, and Groothuis GM (2010) Regulation of VDR expression in rat and human intestine and liver-consequences for CYP3A expression. Toxicol In Vitro 24:822-829. Lampen A, Christians U, Bader A, Hackbarth I, and Sewing KF (1996) Drug interactions and interindividual variability of ciclosporin metabolism in the small intestine. Pharmacology 52:159-168

Läpple F, von Richter O, Fromm MF, Richter T, Thon KP, Wisser H, Griese EU, Eichelbaum M, and Kivistö KT (2003) Differential expression and function of CYP2C isoforms in human intestine and liver. Pharmacogenetics 13:565-575.

Lin YS, Dowling AL, Quigley SD, Farin FM, Zhang J, Lamba J, Schuetz EG, and Thummel KE (2002) Co-regulation of CYP3A4 and CYP3A5 and contribution to hepatic and intestinal midazolam metabolism. Mol Pharmacol 62:162-172.

Lindell M, Karlsson MO, Lennernäs H, Påhlman L, and Lang MA (2003) Variable expression of CYP and Pgp genes in the human small intestine. Eur J Clin Invest 33:493-499.

Lloret-Linares C, Daali Y, Abbara C, Carette C, Bouillot JL, Vicaut E, Czernichow S, and Declèves X (2019) CYP450 activities before and after Roux-en-Y gastric bypass: correlation with thei intestinal and liver content. Surg Obes Relat Dis 15:1299-1310.
Lown KS, Kolars JC, Thummel KE, Barnett JL, Kunze KL, Wrighton SA, and Watkins PB (1994) Interpatient heterogeneity in expression of CYP3A4 and CYP3A5 in small bowel. Lack of prediction by the erythromycin breath test. Drug Metab Dispos 22:947-955.

Madani S, Paine MF, Lewis L, Thummel KE, and Shen DD (1999) Comparison of CYP2D6 content and metoprolol oxidation between microsomes isolated from human livers and small intestines. Pharm Res 16:1199-1205.

Manikandan P and Nagini S (2018) Cytochrome P450 structure, function and clinical significance: a review. Curr Drug Targets 19:38-54.

Matsubara T, Yoshinari K, Aoyama K, Sugawara M, Sekiya Y, Nagata K, and Yamazoe Y (2008) Role of vitamin D receptor in the lithocholic acid-mediated CYP3A induction in vitro and in vivo. Drug Metab Dispos 36:2058-2063.

Misaka S, Kawabe K, Onoue S, Werba JP, Giroli M, Tamaki S, Kan T, Kimura J, Watanabe H, and Yamada S (2013) Effects of green tea catechins on cytochrome P450 2B6, 2C8, 2C19, 2D6 and 3A activities in human liver and intestinal microsomes. Drug Metab Pharmacokinet 28:244-249.

Miyauchi E, Tachikawa M, Declèves X, Uchida Y, Bouillot JL, Poitou C, Oppert JM, Mouly S, Bergmann JF, Terasaki T, et al. (2016) Quantitative atlas of cytochrome P450, UDP-glucuronosyltransferase, and transporter proteins in jejunum of morbidly obese subjects. Mol Pharm 13:2631-2640.

Morgan ET, Goralski KB, Piquette-Miller M, Renton KW, Robertson GR, Chaluvadi MR, Charles KA, Clarke SJ, Kacevska M, Liddle C, et al. (2008) Regulation of drug-metabolizing enzymes and transporters in infection, inflammation, and cancer. Drug Metab Dispos 36:205-216.

Moriyama B, Obeng AO, Barbarino J, Penzak SR, Henning SA, Scott SA, Agúndez J, Wingard JR, McLeod HL, Klein TE, et al. (2017) Clinical Pharmacogenetics Implementation Consortium (CPIC) guidelines for CYP2C19 and voriconazole therapy. Clin Pharmacol Ther 102:45-51.

Obach RS, Zhang QY, Dunbar D, and Kaminsky LS (2001) Metabolic characterization of the major human small intestinal cytochrome P450s. Drug Metab Dispos 29:347-352.

Paine MF, Hart HL, Ludington SS, Haining RL, Rettie AE, and Zeldin DC (2006) The human intestinal cytochrome P450 "pie". Drug Metab Dispos 34:880-886.

Paine MF, Khalighi M, Fisher JM, Shen DD, Kunze KL, Marsh CL, Perkins JD, and Thummel KE (1997) Characterization of interintestinal and intraintestinal variations in human CYP3Adependent metabolism. J Pharmacol Exp Ther 283:1552-1562.

Pavek P and Dvorak Z (2008) Xenobiotic-induced transcriptional regulation of xenobiotic metabolizing enzymes of the cytochrome P450 superfamily in human extrahepatic tissues. Curr Drug Metab 9:129-143.

Rubin K, Janefeldt A, Andersson L, Berke Z, Grime K, and Andersson TB (2015) HepaRG cells as human-relevant in vitro model to study the effects of inflammatory stimuli on cytochrome P450 isoenzymes. Drug Metab Dispos 43:119-125.

Shah RR and Smith RL (2015) Inflammation-induced phenoconversion of polymorphic drug metabolizing enzymes: hypothesis with implications for personalized medicine. Drug Metab Dispos 43:400-410.

Shimada T, Yamazaki H, Mimura M, Inui Y, and Guengerich FP (1994) Interindividual variations in human liver cytochrome P-450 enzymes involved in the oxidation of drugs, carcinogens and toxic chemicals: studies with liver microsomes of 30 Japanese and 30 Caucasians. J Pharmacol Exp Ther 270:414-423.

Spaggiari D, Geiser L, Daali Y, and Rudaz S (2014) A cocktail approach for assessing the in vitro activity of human cytochrome P450s: an overview of current methodologies. J Pharm Biomed Anal 101:221-237.

Thirumaran RK, Lamba JK, Kim RB, Urquhart BL, Gregor JC, Chande N, Fan Y, Qi A, Cheng C, Thummel KE, et al. (2012) Intestinal CYP3A4 and midazolam disposition in vivo associate with VDR polymorphisms and show seasonal variation. Biochem Pharmacol 84:104-112.

Thorn CF, Aklillu E, Klein TE, and Altman RB (2012) PharmGKB summary: very importan pharmacogene information for CYP1A2. Pharmacogenet Genomics 22:73-77.

Tian DD, Natesan S, White JR Jr, and Paine MF (2019) Effects of common CYPIA2 genotypes and other key factors on intraindividual variation in the caffeine metabolic ratio: an exploratory analysis. Clin Transl Sci 12:39-46.

Ulvestad M, Skottheim IB, Jakobsen GS, Bremer S, Molden E, Asberg A, Hjelmesæth J, Andersson TB, Sandbu R, and Christensen H (2013) Impact of OATP1B1, MDR1, and CYP3A4 expression in liver and intestine on interpatient pharmacokinetic variability of atorvastatin in obese subjects. Clin Pharmacol Ther 93:275-282.

von Richter O, Burk O, Fromm MF, Thon KP, Eichelbaum M, and Kivistö KT (2004) Cytochrome P450 3A4 and P-glycoprotein expression in human small intestinal enterocytes and hepatocytes: a comparative analysis in paired tissue specimens. Clin Pharmacol Ther 75:172-183.

Wegler C, Gaugaz FZ, Andersson TB, Wiśniewski JR, Busch D, Gröer C, Oswald S, Norén A Weiss F, Hammer HS, et al. (2017) Variability in mass spectrometry-based quantification of clinically relevant drug transporters and drug metabolizing enzymes. Mol Pharm 14:3142-3151.

Wolbold R, Klein K, Burk O, Nüssler AK, Neuhaus P, Eichelbaum M, Schwab M, and Zanger UM (2003) Sex is a major determinant of CYP3A4 expression in human liver. Hepatology 38:978-988. Wortham M, Czerwinski M, He L, Parkinson A, and Wan YJ (2007) Expression of constitutive androstane receptor, hepatic nuclear factor $4 \alpha$, and P450 oxidoreductase genes determines interindividual variability in basal expression and activity of a broad scope of xenobiotic metabolism genes in the human liver. Drug Metab Dispos 35:1700-1710.

Yang J, He MM, Niu W, Wrighton SA, Li L, Liu Y, and Li C (2012) Metabolic capabilities of cytochrome P450 enzymes in Chinese liver microsomes compared with those in Caucasian liver microsomes. Br J Clin Pharmacol 73:268-284.

Yang X, Zhang B, Molony C, Chudin E, Hao K, Zhu J, Gaedigk A, Suver C, Zhong H, Leeder JS, et al. (2010) Systematic genetic and genomic analysis of cytochrome P450 enzyme activities in human liver. Genome Res 20:1020-1036.

Zanger UM and Schwab M (2013) Cytochrome P450 enzymes in drug metabolism: regulation of gene expression, enzyme activities, and impact of genetic variation. Pharmacol Ther 138:103-141.

Zhang H, Gao N, Liu T, Fang Y, Qi B, Wen Q, Zhou J, Jia L, and Qiao H (2015) Effect of cytochrome b5 content on the activity of polymorphic CYP1A2, 2B6, and 2E1 in human liver microsomes. PLoS One 10:e128547.

Zhang HF, Li ZH, Liu JY, Liu TT, Wang P, Fang Y, Zhou J, Cui MZ, Gao N, Tian X, et al. (2016) Correlation of cytochrome P450 oxidoreductase expression with the expression of 10 isoforms of cytochrome P450 in human liver. Drug Metab Dispos 44:1193-1200.

Address correspondence to: Veronica Krogstad, Section for Pharmacology and Pharmaceutical Biosciences, Department of Pharmacy, University of Oslo, P.O. Box 1068, Blindern, 0316 Oslo, Norway. E-mail: veronica.krogstad@farmasi.uio.no 